\title{
The role of dexamethasone in scorpion venom-induced deregulation of sodium and water transport in rat lungs
}

Ceila Maria Sant Ana Malaque ${ }^{1,2^{*}}$, Ana Carolina de Bragança ${ }^{1}$, Talita Rojas Sanches ${ }^{1}$, Rildo Aparecido Volpini ${ }^{1}$, Maria Heloisa Shimizu', Meire loshie Hiyane ${ }^{3}$, Niels Olsen Saraiva Câmara ${ }^{3}$, Antonio Carlos Seguro ${ }^{1}$ and Lucia Andrade ${ }^{1}$

\author{
* Correspondence: \\ ceila.malaque@butantan.gov.br \\ ${ }^{1}$ Nephrology Department, University \\ of São Paulo School of Medicine, \\ São Paulo, Brazil \\ ${ }^{2}$ Vital Brazil Hospital, Butantan \\ Institute, São Paulo, Brazil \\ Full list of author information is \\ available at the end of the article
}

Background: Severe scorpion envenomation can evolve to lung injury and, in some cases, death. The lung injury could be attributed to acute left ventricular failure and increased pulmonary vascular permeability secondary to the release of inflammatory mediators. In clinical practice, corticosteroids have been administered to reduce the early side effects of the anti-venom. We propose to study the effects of Tityus serrulatus venom and dexamethasone on pulmonary expression of sodium and water transporters, as well as on the inflammatory response.

Methods: Wistar rats were injected intraperitoneally with saline (control group), dexamethasone, and saline (2.0 mg/kg body weight-60 min before saline injection; dexamethasone + saline group), venom (T. serrulatus venom-3.8 mg/kg body weight), or dexamethasone and venom $(2.0 \mathrm{mg} / \mathrm{kg}$ body weight $-60 \mathrm{~min}$ before venom injection; dexamethasone + venom group). At $60 \mathrm{~min}$ after venom/saline injection, experiments were performed in ventilated and non-ventilated animals. We analyzed sodium transporters, water transporters, and Toll-like receptor 4 (TLR4) by Western blotting, macrophage infiltration by immunohistochemistry, and serum interleukin (IL) by cytokine assay.

Results: In the lung tissue of non-ventilated envenomed animals, protein expression of the epithelial sodium channel alpha subunit (a-ENaC) and aquaporin 5 (AQP5) were markedly downregulated whereas that of the Na-K-2Cl cotransporter (NKCC1) and TLR4 was elevated although expression of the Na,K-ATPase alpha 1 subunit was unaffected. Dexamethasone protected protein expression of a-ENaC, NKCC1, and TLR4 but not that of AQP5. We found that IL-6, IL-10, and tumor necrosis factor alpha were elevated in the venom and dexamethasone + venom groups although CD68 expression in lung tissue was elevated only in the venom group. Among the ventilated animals, both envenomed groups presented hypotension at 50 min after injection, and the arterial oxygen tension/ fraction of inspired oxygen ratio was lower at 60 min than at baseline.

Conclusions: Our results suggest that $T$. serrulatus venom and dexamethasone both regulate sodium transport in the lung and that $T$ serrulatus venom regulates sodium transport via the TLR4 pathway.

Keywords: Scorpion venoms; Pulmonary edema/metabolism; Pulmonary alveoli; Cytokines; Toll-like receptor 4

\section{Springer}

(C) 2015 Malaque et al. Open Access This article is distributed under the terms of the Creative Commons Attribution 4.0 International License (http://creativecommons.org/licenses/by/4.0/), which permits unrestricted use, distribution, and reproduction in any medium provided you give appropriate credit to the original author(s) and the source, provide a link to the Creative Commons license, and indicate if changes were made. 


\section{Background}

In tropical and subtropical countries, scorpion envenomation is common and sometimes fatal, especially among children $[1,2]$. The incidence and severity of such envenomation are remarkable in Africa, the Near- and Middle-East, Mexico; Brazil, the Amazon basin, and southern India [1]. In Brazil, approximately 78,000 scorpion stings are reported annually [3]. Tityus serrulatus is considered the most medically important scorpion species in Brazil. Although most cases of scorpion envenomation occur in adults, the most severe cases are in children, in whom mortality is also higher [4].

The clinical manifestations of envenomation by scorpions of the genera Androctonus, Leiurus, Buthus, Centruroides, and Tityus are quite similar, including pain, persistent nausea, vomiting, hypertension, tachycardia, tachypnea, and prostration. Patients presenting with severe envenomation can also progress to heart failure, pulmonary edema, and shock [4-8]. Most of the symptoms and signs of scorpion envenomation have been attributed to the effects of the venom interacting with sodium channels and of neurotransmitters released from autonomic nerve endings $[9,10]$. In severe cases, lung injury is common and is frequently the cause of death [11]. Two distinct mechanisms have been suggested to explain the development of pulmonary edema: acute left ventricular failure resulting from massive catecholamine release $[12,13]$ and increased pulmonary vascular permeability following the release of inflammatory mediators, such as plateletactivating factor, leukotrienes, and prostaglandins [14-16]. Increased serum levels of pro- and anti-inflammatory cytokines, such as interleukin (IL)-1, IL-6, tumor necrosis factor alpha (TNF- $\alpha$ ), and IL-10, have also been observed following T. serrulatus envenomation in animals and humans [17-20].

Regardless of its pathogenesis, pulmonary edema is resolved by active sodium transport across the alveolar epithelium via apical amiloride-sensitive sodium channels and basolateral Na,K-ATPase. This active vectorial sodium transport produces a transepithelial osmotic gradient that results in passive movement of water from the air spaces into the alveolar interstitium [21, 22]. In some models of acute lung injury, as well as in patients with acute respiratory distress syndrome, the ability of the lungs to clear edema is impaired [23]. In rats injected with the T. serrulatus venom, alveolar fluid clearance is decreased by up to $60 \%$. In addition, the expression and activity of Na,K-ATPase subunits have been shown to decrease in the basolateral membranes of alveolar type II epithelial cells incubated with scorpion venom [24].

Because they can recognize pathogen-associated molecules, Toll-like receptors (TLRs) are key components in human innate immune responses. In contrast with the adaptive immune system, the innate immune system uses TLRs to react rapidly to a wide range of pathogenassociated molecular patterns, without prior exposure. TLRs were initially characterized by their interactions with bacterial ligands and involvement in the cellular activation associated with infection and sepsis. However, recent studies have shown that TLR2 and TLR4 can recognize non-microbial ligands. Once activated, TLRs induce the production of inflammatory cytokines, such as TNF- $\alpha$, IL- $1 \beta$, and IL-6, through an intracellular signaling cascade [25].

In Brazil, it is common to administer corticosteroids prior to the administration of anti-venom [4]. Therefore, the objective of the present study was to evaluate, in rats inoculated with $T$. serrulatus venom, the effects that dexamethasone has on the early clinical, biochemical, and ventilatory parameters, on initial molecular changes in the 
expression of sodium and water transporters, and on the early inflammatory response.

\section{Methods}

Animals, experimental materials, and procedures

Adult male Wistar rats weighing 215-250 g were obtained from the animal facilities of the University of São Paulo School of Medicine, provided food and water ad libitum, and maintained on a 12/12-h light/dark cycle.

Venom (from T. serrulatus), provided by the Butantan Institute (São Paulo, Brazil), was diluted in sterile saline, aliquoted, and stored at $-70{ }^{\circ} \mathrm{C}$. Sodium thiopental and dexamethasone were obtained from Cristália (São Paulo, Brazil). We generated a doseresponse curve. We found that intraperitoneal (ip) injection of $3.8 \mathrm{mg} / \mathrm{kg}$ body weight $(\mathrm{BW})$ of crude scorpion venom-induced rats to severe envenomation. Rats were divided into the following groups: venom, comprising rats receiving $3.8 \mathrm{mg}$ of venom $/ \mathrm{kg} \mathrm{BW}$ (ip); dexamethasone + venom, comprising rats receiving $2.0 \mathrm{mg} / \mathrm{kg} \mathrm{BW}$ (ip) of dexamethasone [26], 60 min before receiving venom (as above); and control, comprising rats receiving $0.5 \mathrm{ml}$ of saline (ip). Two sets of experiments were performed. In the first set, we used non-ventilated animals ( 8 control group rats, 13 venom group rats, and 11 dexamethasone + venom group rats). In the second set, we used ventilated animals (7 control group rats, 6 venom group rats, and 5 dexamethasone + venom group rats).

An additional group of control rats receiving only dexamethasone $(2.0 \mathrm{mg} / \mathrm{kg})$ was evaluated in order to determine the effects of the drug on biochemical and ventilatory parameters.

All procedures were performed in compliance with Brazilian Ethics Committee for Animal Experimentation (Federal Law n.11.794, October 8th, 2008, Arouca Act), and all experimental procedures were approved by the University of São Paulo School of Medicine Animal Research Committee (number 515/09).

\section{Non-ventilated animals}

\section{Procedures}

After injection(s), non-ventilated rats were monitored for $60 \mathrm{~min}$, during which time we analyzed clinical parameters such as lacrimation, salivation, dyspnea, and cyanosis. The survivors were anesthetized with sodium thiopental (50 mg/kg BW). The aorta was cannulated with a PE-60 catheter, and blood samples were collected for biochemical analysis and determination of cytokine levels. The lungs were flushed with phosphatebuffered saline (injected into the aorta), excised, and stored at $-70{ }^{\circ} \mathrm{C}$ for subsequent Western blotting.

\section{Biochemical analysis}

At 60 min after venom administration, plasma levels of $\mathrm{Na}, \mathrm{K}$, urea, creatinine, creatine kinase, lactate dehydrogenase, amylase, and troponin were measured kinetically.

\section{Antibodies}

The peptide-derived polyclonal antibodies specific to the $\mathrm{Na}-\mathrm{K}-2 \mathrm{Cl}$ cotransporter (NKCC1) were kindly supplied by Dr. R. James Turner (National Institute of Dental and Craniofacial Research, Bethesda, MD). The peptide-derived polyclonal antibodies specific to the 
epithelial sodium channel alpha subunit $(\alpha-\mathrm{ENaC})$, the $\mathrm{Na}, \mathrm{K}$-ATPase alpha 1 subunit $\left(\alpha_{1}\right.$ Na,K-ATPase), aquaporin 5 (AQP5), TLR4, and actin were obtained from Santa Cruz Biotechnology (Santa Cruz, CA), and the peptide-derived monoclonal antibodies specific to CD68 were obtained from ABD Serotec (Raleigh, NC).

\section{Membrane fractions}

Samples of lungs were homogenized in ice-cold isolation solution containing protease inhibitors. The homogenates were centrifuged, the supernatants were spun, and the resulting pellets, containing membrane fractions enriched with plasma membranes and intracellular vesicles, were suspended in the isolation solution.

\section{Western blotting}

Samples of membrane fractions were run on $12.5 \%$ polyacrylamide minigels (for AQP5), $10 \%$ polyacrylamide minigels (for $\alpha$-ENaC, $\alpha 1-\mathrm{Na}, \mathrm{K}$-ATPase, and TLR4), or $8 \%$ polyacrylamide minigels (for NKCC1). After transfer by electroelution to nitrocellulose membranes (PolyScreen, PVDF Transfer; Life Science Products, Boston, MA, USA), blots were blocked with $5 \%$ milk and $0.1 \%$ Tween 20 in phosphate-buffered saline for $1 \mathrm{~h}$, then incubated with anti-AQP5 antibody (1:500), NKCC1 antibody (1:1000), $\alpha_{1}$-Na,K-ATPase antibody (1:500), $\alpha$-ENaC antibody (1:100), or TLR4 antibody (1:100). The labeling was visualized with horseradish peroxidase-conjugated secondary antibody (anti-rabbit IgG, diluted 1:5000, or anti-goat IgG, diluted 1:10,000; Sigma) using the enhanced chemiluminescence detection system (Amersham Pharmacia Biotech, Piscataway, NJ, USA). Bands corresponding to protein expression of AQP5, $\alpha-\mathrm{ENaC}, \alpha 1-\mathrm{Na}$,K-ATPase, NKCC1, TLR4, and actin were quantified by densitometric analysis using Image J software (Research Services Branch, National Institutes of Health, Bethesda, MD, USA). Bands were normalized to actin and are expressed as percentages of the control values.

\section{Immunohistochemistry}

Fragments of the lungs from rats of all groups were immersed in $4 \%$ paraformaldehyde, fixed for $2 \mathrm{~h}$, post-fixed in Bouin's solution for $4 \mathrm{~h}$, drained, dehydrated in $70 \%$ ethanol, and processed for paraffin embedding. The samples were sliced into 4- $\mu \mathrm{m}$ histological sections. The sections were incubated overnight at $4{ }^{\circ} \mathrm{C}$ with antibodies against CD68 (1:1000) or AQP5 (1:50). The reaction products were detected with an avidin-biotin-peroxidase complex (Vector Laboratories, Burlingame, CA, USA). The color reactions were developed with 3,3-diaminobenzidine (Sigma) and nickel chloride $(8 \%)$ in the presence of hydrogen peroxide, and the material was then counterstained with methyl green, dehydrated, and mounted. Infiltrating macrophage/monocyte-positive cells were counted in 30 grid fields $\left(0.087 \mathrm{~mm}^{2}\right.$ each). The volume proportion of AQP5 in the alveolar tissue of lung sections was determined by dividing the number of points hitting AQP5 by the total number of points hitting alveolar septa (in 20 fields). Results are expressed as a percentage of positive area per total area of tissue. For counting positive cells, we used the AxioVision program, version 4.8 (Carl Zeiss, Eching, Germany), and we used ImagePro Plus 4.1 (Media Cybernetics, Silver Spring, MD), for measuring area and percentage. 


\section{Inflammatory cytokines}

To determine plasma levels of IL-6, IL-10, and TNF-a, we used a Bio-Plex rat cytokine assay kit (R\&D Systems, Minneapolis, MN, USA). The assay was read on the Bio-Plex suspension array system (Bio-Rad, Hercules, CA, USA), and the data were analyzed with Bio-Plex Manager software, version 6.0 (Millipore, Billerica, MA, USA).

\section{Ventilated animals}

\section{Procedures}

In ventilated rats, we evaluated the following parameters: the arterial oxygen tension/fraction of inspired oxygen $\left(\mathrm{PaO}_{2} / \mathrm{FIO}_{2}\right)$ ratio, bicarbonate and plasma glucose (Fig. 1), mean arterial pressure (MAP), and heart rate (HR). We subtracted the $\mathrm{PaO}_{2} / \mathrm{FiO}_{2}$ at 30 and 60 min from the $\mathrm{PaO}_{2} / \mathrm{FiO}_{2}$ before venom injection because that difference $\left(\Delta \mathrm{PaO} \mathrm{O}_{2} / \mathrm{FiO}_{2}\right)$ is more important than is the absolute $\mathrm{PaO}_{2} / \mathrm{FIO}_{2}$ at either time point.

All animals were submitted of mechanical ventilation at a tidal volume of $10 \mathrm{ml} / \mathrm{kg}$, positive end-expiratory pressure (PEEP) of $3 \mathrm{cmH}_{2} \mathrm{O}, \mathrm{FIO}_{2}$ of $50 \%$, and respiratory rate of $60 \mathrm{breaths} / \mathrm{min}$. Animals were anesthetized with thiopental (50 mg/kg BW ip) and underwent tracheotomy. The right carotid artery was cannulated with a PE-60 catheter in order to determine MAP, as well as to allow blood sampling at the various time points. The left jugular vein was also cannulated with a PE-60 catheter for the infusion of drugs and venom. The rats were connected to a small animal ventilator (Atlanta; Takaoka, São Paulo, Brazil). Pancuronium (1 ml/kg BW ip) was then administered. To allow the animals to stabilize, we did not initiate the experiment until 15 min after the tracheotomy (Fig. 1). After stabilization, the control and venom groups received saline, whereas the dexamethasone + venom group received dexamethasone diluted in saline. In order to evaluate the effects of dexamethasone in the ventilated animals, we determined serum glycemia and arterial blood gases at 60 min after the initiation of mechanical ventilation, immediately prior to envenomation.

\section{Arterial blood sampling and hemodynamic evaluation}

Arterial blood gases and glucose were analyzed with a blood gas analyzer (ABL800 FLEX; Radiometer, Copenhagen, Denmark). In addition, heart rate and MAP were continually monitored with an invasive constant monitoring probe (MP100; Biopac Systems, Goleta, CA, USA).

\section{Statistical analysis}

All quantitative data are expressed as mean \pm SEM. Comparisons between proportions were analyzed by chi-square test or Fisher's exact test. Differences among the means of

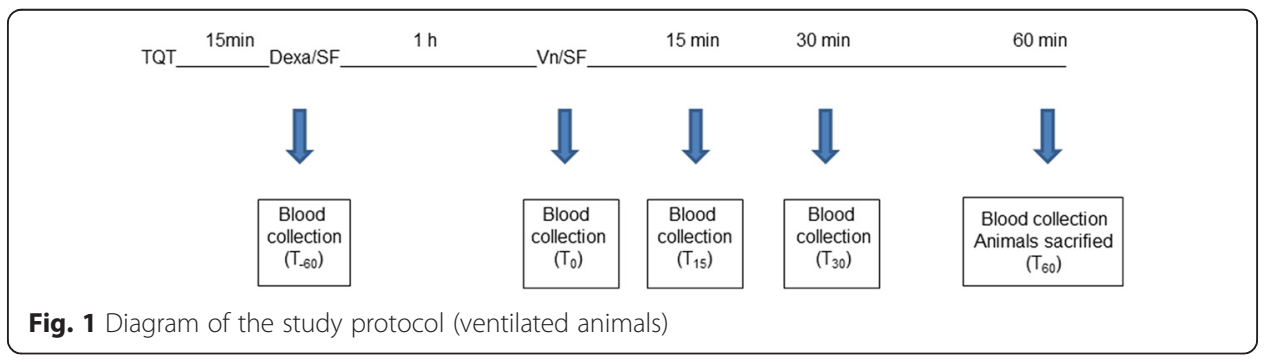


multiple parameters were analyzed by ANOVA followed by the Student-Newman-Keuls test. Values of $p \leq 0.05$ were considered statistically significant.

\section{Results}

\section{Non-ventilated animals}

\section{Clinical data}

Some venom-injected rats exhibited systemic manifestations, as early as $30 \mathrm{~min}$ after the injection, including lacrimation, salivation, dyspnea, cyanosis, and chromodacryorrhea. Of the 13 venom group rats, 1 (7.7 \%) died before the end of the 60-min observation period and $4(30.8 \%)$ showed no clinical manifestations consistent with severe poisoning, compared with $2(18.2 \%)$ and $4(36.4 \%)$ of the 11 dexamethasone + venom group rats (NS).

\section{Biochemical data}

Serum potassium levels were lower in the venom and dexamethasone + venom groups than in the control and dexamethasone groups. Serum amylase levels were higher in the dexamethasone + venom group than in the other groups (Table 1).

\section{Sodium and water transporters in lungs}

Figure 2 shows that $\alpha$-ENaC expression in the venom group ( $43.2 \pm 7.3 \%)$ was lower than in the control group $(91.5 \pm 8.5 \%)$ and dexamethasone + venom group $(78.6 \pm 18 \%)$, the differences being significant ( $p<0.05$ for both). Semiquantitative immunoblotting revealed that pulmonary expression of $\alpha_{1}$-Na,K-ATPase was comparable across the venom, dexamethasone + venom, and control groups $(102.5 \pm 7.2,102.8 \pm 7.6$, and $95.3 \pm 6.0 \%$, respectively).

As shown in Fig. 2, pulmonary NKCC1 expression in the venom group (146.2 $\pm 4.5 \%)$ was significantly higher than in the control group $(98.5 \pm 7.4 \%, p<0.01)$ and dexamethasone + venom group $(63.6 \pm 15.6 \%, p<0.001)$, the dexamethasone + venom value being significantly lower than that obtained for the control group $(p<0.05)$.

Figures $3 \mathrm{a}, \mathrm{b}$ shows that pulmonary expression of AQP5 was significantly lower in the venom and dexamethasone + venom rats than in the controls (46.0 \pm 5.8 and $43.9 \pm 8.6 \%$ vs. $100.1 \pm 9.2 \%, p<0.05)$. In accordance with the protein expression results, the immunohistochemical staining for AQP5 was less intense and less extensive in the venom and dexamethasone + venom groups than in the control group (Fig. 3C1-C3).

\section{Macrophage infiltration}

At $60 \mathrm{~min}$ after venom administration, the number of cells presenting CD68 staining for macrophages/monocytes in the lung (Fig. 4) was significantly higher in the venom group than in the control group (51.9 \pm 6.9 vs. $23.2 \pm 1.3$ cells $\left./ 0.087 \mathrm{~mm}^{2}, p<0.05\right)$. The number obtained for the dexamethasone + venom group $\left(39.4 \pm 3.8\right.$ cells $\left./ 0.087 \mathrm{~mm}^{2}\right)$ did not differ significantly from those obtained for the other groups.

\section{TLR4 expression}

As shown in Fig. 5, TLR4 expression was significantly higher in venom rats than that in control and dexamethasone + venom rats $(194 \pm 17.5 \%$ vs. $100.6 \pm 5.2$ and $106.3 \pm$ $12.3 \%, p<0.05$ for both). 
Table 1 Biochemical data for non-ventilated rats after administration of saline, dexamethasone, T. serrulatus venom, or dexamethasone plus T. serrulatus venom

\begin{tabular}{|c|c|c|c|c|c|c|c|c|}
\hline \multirow[t]{2}{*}{ Group } & $\mathrm{Na}$ & K & Urea & Creatinine & Amylase & CK & $\mathrm{LDH}$ & Troponin \\
\hline & $\mathrm{mEq} / \mathrm{L}$ & $\mathrm{mEq} / \mathrm{L}$ & $\mathrm{mg} / \mathrm{dl}$ & $\mathrm{mg} / \mathrm{dl}$ & $\mathrm{U} / \mathrm{L}$ & $\mathrm{U} / \mathrm{L}$ & $U / L$ & $\mathrm{ng} / \mathrm{ml}$ \\
\hline Control & $143.1 \pm 2.3$ & $4.3 \pm 0.2$ & $38.9 \pm 2.6$ & $0.3 \pm 0.0$ & $2210.0 \pm 89.5$ & $572.4 \pm 66.1$ & $623.0 \pm 187.2$ & $0.2 \pm 0.2$ \\
\hline Dx & $148.5 \pm 0.96$ & $3.7 \pm 0.2$ & $46.8 \pm 3.8$ & $0.2 \pm 0.0$ & $2268.0 \pm 146.3$ & $532.0 \pm 84.7$ & $385.0 \pm 49.6$ & $0.0 \pm 0.0$ \\
\hline$V_{n}$ & $140.6 \pm 2.4$ & $3.2 \pm 0.1^{*}$ & $44.4 \pm 5.4$ & $0.3 \pm 0.0$ & $2311.0 \pm 112.2$ & $630.8 \pm 118.5$ & $525.4 \pm 129.2$ & $0.1 \pm 0.1$ \\
\hline$D x+V n$ & $142.3 \pm 1.4$ & $3.4 \pm 0.2^{*}$ & $55.5 \pm 13.1$ & $0.3 \pm 0.1$ & $3213.0 \pm 338.5^{* *}$ & $761.0 \pm 140.8$ & $586.3 \pm 97.4$ & $0.0 \pm 0.0$ \\
\hline
\end{tabular}

$C K$ creatine kinase, $L D H$ lactate dehydrogenase, $D x$ dexamethasone, $V n$ venom, $D x+V n$ dexamethasone + venom

${ }^{*} p<0.05$ compared with control

${ }^{*} p<0.05$ compared with control 


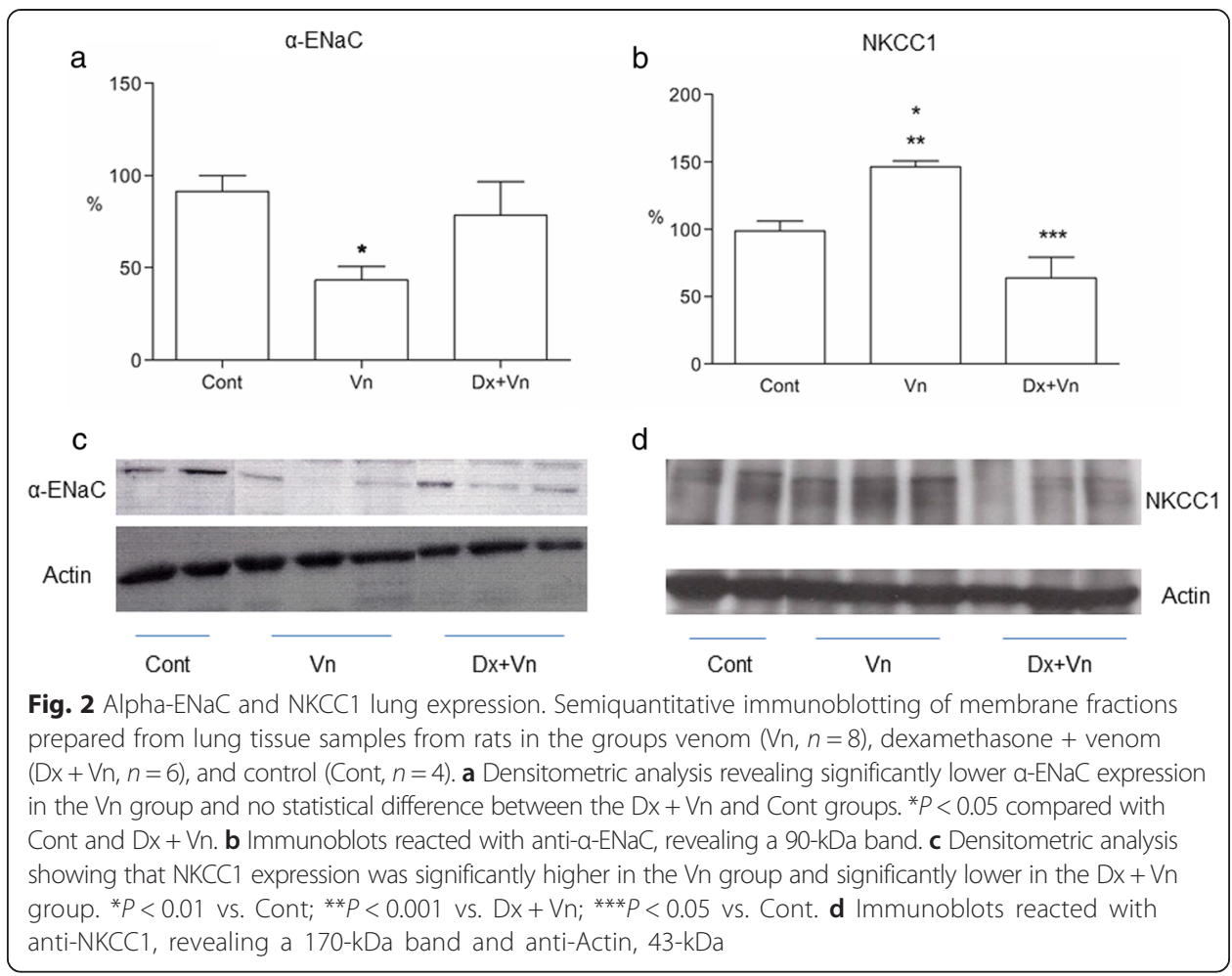

\section{Plasma cytokine levels}

Plasma cytokine levels (in $\mathrm{pg} / \mathrm{ml}$ ) were significantly higher in the venom and dexamethasone + venom groups than in the control group-IL-6, $114.9 \pm 21.4$ and $108.9 \pm 8.9$ vs. $88.8 \pm 49.2$; TNF- $\alpha, 11.84 \pm 0.0$ and $11.54 \pm 0.0$ vs. $5.9 \pm 3.3$; and IL-10, $42.6 \pm 9.0$ and $35.7 \pm 6.8$ vs. $10.0 \pm 2.4-(p<0.05$ for all $)$.

\section{Ventilated animals \\ Clinical data}

After 60 min on mechanical ventilation (immediately before venom or saline administration) (Fig. 1), the biochemical, respiratory and hemodynamic parameters in the dexamethasone group did not differ from those observed in the control group: glycemia $-120.0 \pm 4.4$ vs. $125.2 \pm 4.3$ (NS); bicarbonate $-18.2 \pm 0.7$ vs. $18.2 \pm 0.4$ (NS); $\Delta \mathrm{PaO}_{2} / \mathrm{FIO}_{2}\left(\mathrm{~T}_{0}-\mathrm{T}_{-60}\right)-7.2 \pm 9.7$ vs. $10.0 \pm 6.0(\mathrm{NS}) ; \mathrm{MAP}-142.0 \pm 1.9$ vs. $142.0 \pm 5.8$ (NS); HR-493.8 \pm 21.5 vs. $503.0 \pm 8.3$ (NS).

\section{Biochemical data}

Hyperglycemia was seen in the venom and dexamethasone + venom groups. In both groups, the levels of glycemia were highest at $30 \mathrm{~min}$ after venom injection (Table 2).

\section{Respiratory and hemodynamic parameters}

At $60 \mathrm{~min}$ after venom injection, the greater $\Delta \mathrm{PaO} 2 / \mathrm{FIO} 2$ (i.e., the difference between the $\mathrm{PaO}_{2} / \mathrm{FIO}_{2}$ values obtained immediately before and 60 min after envenomation) indicates that $\mathrm{PaO} 2 / \mathrm{FIO} 2$ was worse in both envenomed groups than in the control 


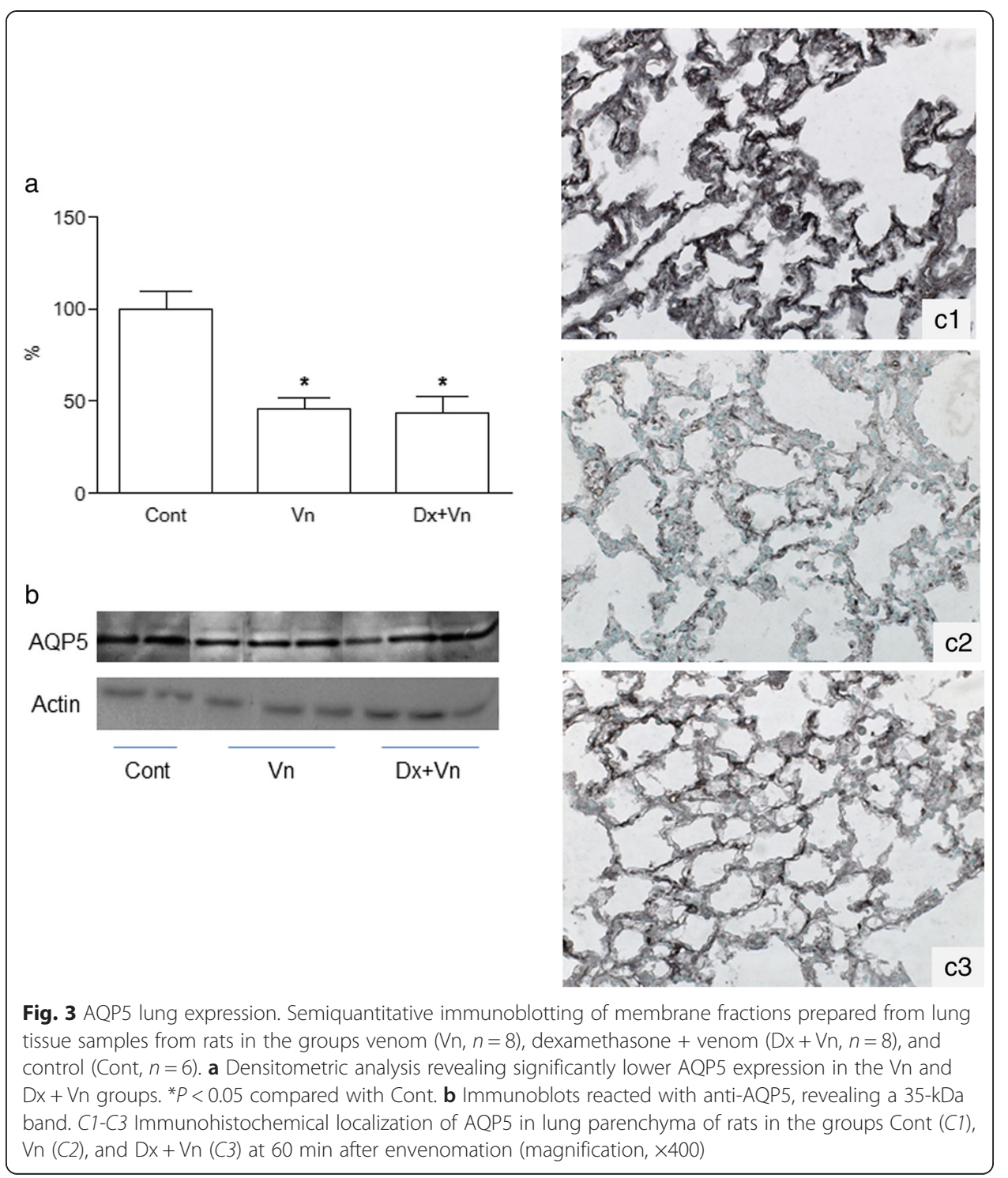

group (Table 2). At 50 min after venom administration, the animals in both envenomed groups presented hypotension, whereas the control group animals did not. Although we expected the hypotension seen in the envenomed groups to increase heart rates, we found no statistical differences in heart rate among the groups (Fig. 6). However, the mean heart rate was slightly higher in the dexamethasone + venom group, a difference that trended toward significance in comparison with the other groups. In order to analyze the acid-base status, we measured plasma bicarbonate levels. At 30 and $60 \mathrm{~min}$ after venom administration, plasma bicarbonate levels were lower in the venom and dexamethasone + venom groups than in the control group (Table 2).

\section{Discussion}

The animal model used in the present study, which involved a high dose of scorpion venom, mimicked the physiological manifestations of severe human envenomation [6, 27], provoking altered expression of sodium and water transporters in lung tissue. 

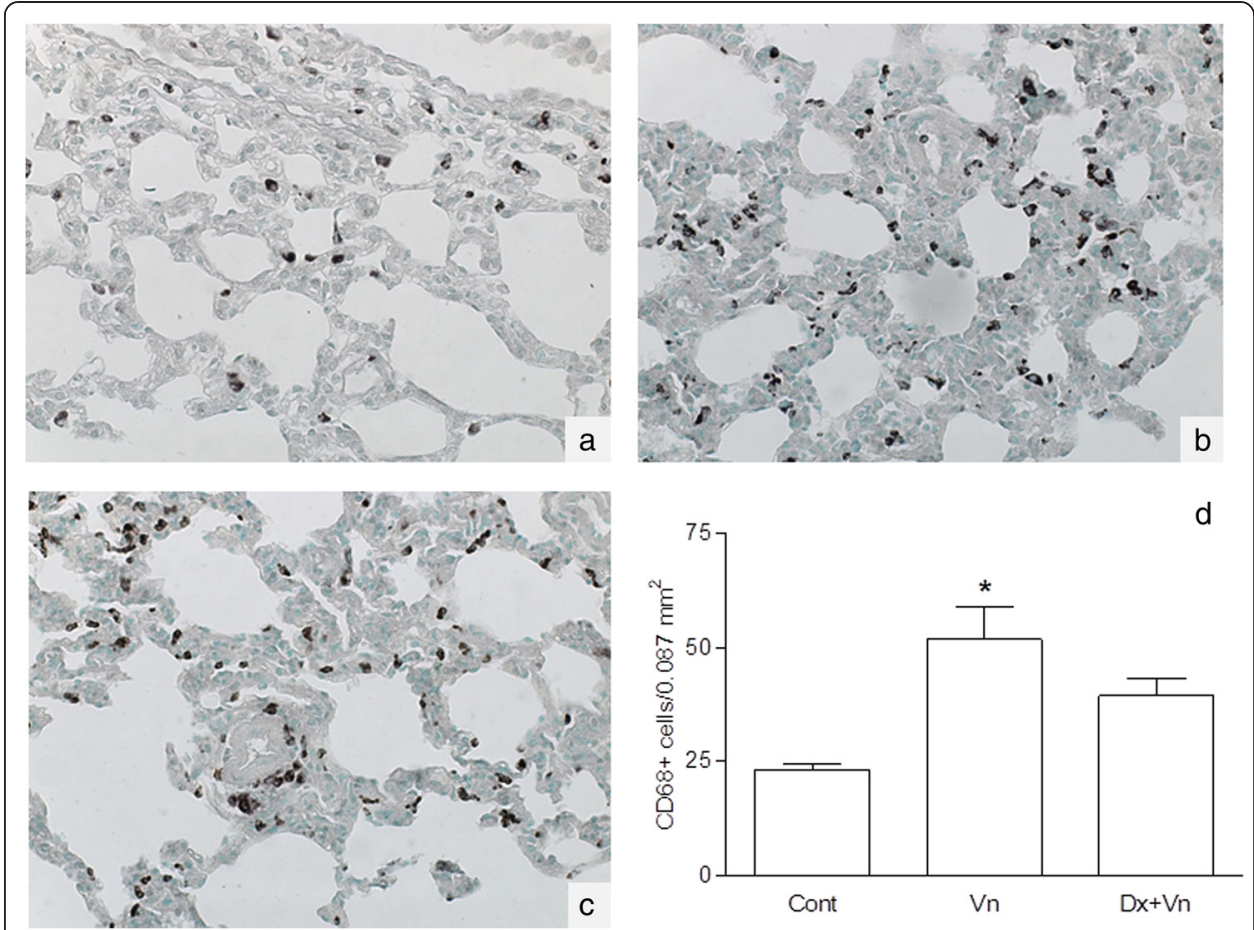

Fig. 4 Alveolar macrophage infiltration. Alveolar infiltration by CD68-positive cells (cells/0.087 mm²) at 60 min after envenomation in tissue samples from rats in the groups venom $(V n, n=5)$, dexamethasone + venom $(\mathrm{Dx}+\mathrm{Vn}, n=5)$, and control (Cont, $n=3)$. Immunostaining for CD68 in the Cont (a), $\mathrm{Vn}_{\mathrm{n}}(\mathbf{b})$, and $\mathrm{Dx}+\mathrm{Vn}_{\mathrm{n}}(\mathbf{c})$ groups (magnification, $\times 400$ for all). CD68-positive cell counts (mean \pm SEM), showing that alveolar macrophage infiltration was significantly greater in the $V n$ group $(\mathbf{d}) .{ }^{*} P<0.05$ compared with Cont

a

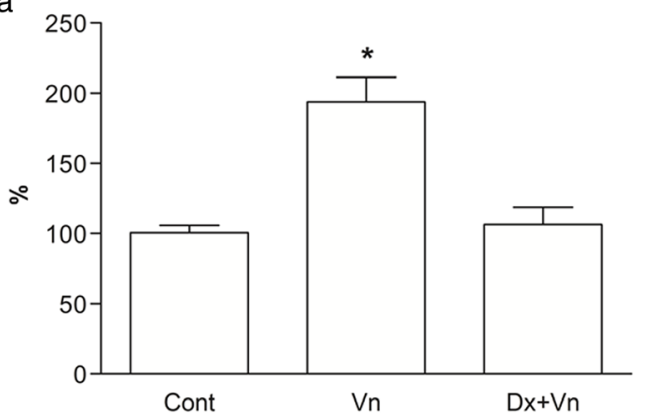

b

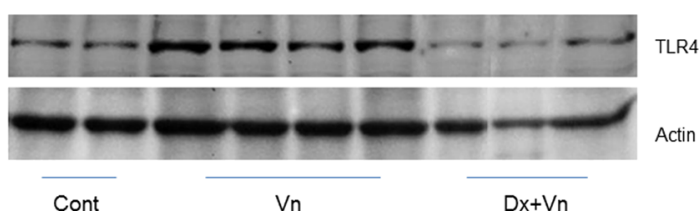

Fig. 5 TLR4 lung expression. Semiquantitative immunoblotting of membrane fractions prepared from lung tissue samples from rats in the groups venom $(V n, n=5)$, dexamethasone + venom $(D x+V n, n=4)$, and control (Cont, $n=5$ ). a Densitometric analysis revealing significantly higher TLR4 expression in the $V n$ group. ${ }^{*} P<0.05$ compared with Cont and Dx + Vn. b Immunoblots reacted with anti-TLR4, revealing an 89-kDa band 
Table 2 Metabolic parameters in ventilated animals

\begin{tabular}{|c|c|c|c|c|c|c|c|c|}
\hline \multirow[t]{2}{*}{ Group } & \multicolumn{2}{|c|}{$\Delta \mathrm{PaO}_{2} / \mathrm{FIO}_{2}$} & \multicolumn{3}{|c|}{ Bicarbonate (mEq/L) } & \multicolumn{3}{|c|}{ Glucose (mg/dl) } \\
\hline & $T_{30}-T_{0}$ & $T_{60}-T_{0}$ & $\mathrm{~T}_{0}$ & $\mathrm{~T}_{30}$ & $T_{60}$ & $\mathrm{~T}_{0}$ & $T_{30}$ & $T_{60}$ \\
\hline Control & $3.5 \pm 3.2$ & $14.0 \pm 6.3$ & $21.3 \pm 0.6$ & $17.8 \pm 0.6$ & $18.5 \pm 0.4$ & $119.2 \pm 0.9$ & $110.3 \pm 8.6$ & $106.7 \pm 5.9$ \\
\hline$V_{n}$ & $-11.0 \pm 6.1$ & $-14.8 \pm 4.3^{*}$ & $20.0 \pm 0.7$ & $12.8 \pm 0.4^{*}$ & $11.5 \pm 0.4^{*}$ & $121.8 \pm 2.0$ & $249.8 \pm 12.3^{*}$ & $189.8 \pm 23.0^{*}$ \\
\hline$x+V n$ & $-14.7 \pm 11.9$ & $-9.0 \pm 7.9^{*}$ & $19.9 \pm 0.4$ & $13.3 \pm 1.2^{*}$ & $12.8 \pm 1.6^{*}$ & $119.3 \pm 4.8$ & $245.3 \pm 24.0^{*}$ & $166.8 \pm 27.9^{*}$ \\
\hline
\end{tabular}

$\triangle \mathrm{PaO}_{2} / \mathrm{FIO}_{2}$ delta arterial oxygen tension/fraction of inspired oxygen $\left(\mathrm{T}_{30}\right.$ minus $\mathrm{T}_{0} ; \mathrm{T}_{60}$ minus $\left.\mathrm{T}_{0}\right), T_{0}$ immediately before envenomation, $T_{30} 30 \mathrm{~min}$ after envenomation, $T_{60} 60 \mathrm{~min}$ after envenomation, $V n$ venom, $D x+V n$ dexamethasone + venom ${ }^{*} p<0.05$ compared with control

The hyperamylasemia observed in the dexamethasone + venom group might be attributable to synergism between the dexamethasone and the high dose of venom, given that no hyperamylasemia was observed in the venom or dexamethasone groups. This suggests a potential adverse effect of corticosteroid administration in the absence of specific antivenom administration.

In extremely severe cases of scorpion envenomation, pulmonary edema is common and may lead to death. In some cases, pulmonary edema can persist even $24 \mathrm{~h}$ after anti-venom administration [28]. Pulmonary edema is more affected by active sodium transport out of the alveoli than by the reversal of Starling forces. In alveolar epithelial cells, T. serrulatus venom downregulates $\mathrm{Na}, \mathrm{K}-\mathrm{ATPase}$ [24]. In our study, T. serrulatus venom decreased expression of $\alpha-\mathrm{ENaC}$ and AQP5, as well as upregulating basolateral NKCC1, although $\alpha_{1}$ $\mathrm{Na}$,K-ATPase expression was unaffected. Impaired fluid handling can hinder pulmonary function and increase the susceptibility of the lung to injury [22]. Active transport by the $\mathrm{Na}$,K-ATPase pump generates an osmotic driving force favorable to the entrance of sodium
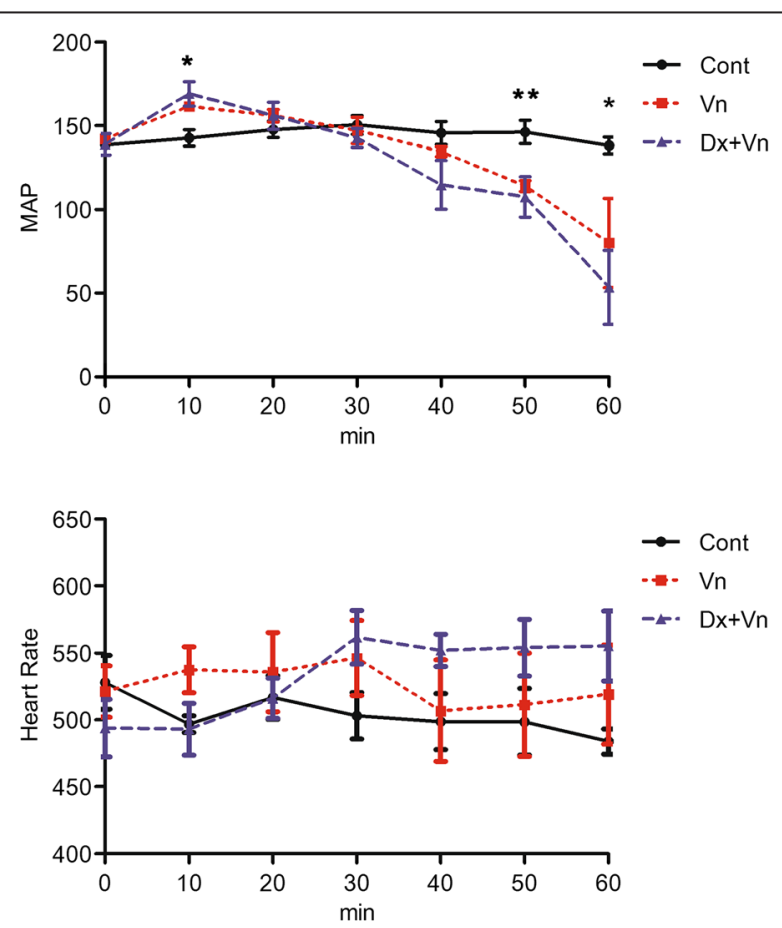

Fig. 6 Hemodynamic variation during envenomation. Effect of Tityus serrulatus venom administration on mean arterial pressure and heart rate in the venom $(V n)$, dexamethasone + venom $(D x+V n)$ and control (Cont) groups. ${ }^{*} P<0.05$ for $\mathrm{Dx}+\mathrm{Vn}$ vs. Cont, ${ }^{* *} P<0.05$ for $\mathrm{Vn}$ and $\mathrm{Dx}+\mathrm{Vn}$ vs. Cont) 
via $\alpha$-ENaC. There is therefore continuous transport of sodium from the lumen into the interstitial space [29]. Volume is regulated primarily by electroneutral cotransporters such as NKCC1, which is found in virtually all cells and mediates the coupled influx of sodium, potassium, and chlorine. The mechanism by which cell shrinkage activates NKCC1 is unknown [30]. We hypothesized that $T$. serrulatus venom might impair pulmonary fluid transport because it decreases $\alpha-\mathrm{ENaC}$ and AQP5 expression, as well as increases NKCC1 expression. Although it has been demonstrated that AQP5 knockout mice show the same pulmonary fluid transport as do control mice [31-33], it is possible that, in association with altered sodium transporter expression, decreased AQP5 expression impairs pulmonary fluid transport in severe scorpion envenomation.

In Brazil, it is common to give corticosteroids prior to the administration of antivenom [4]. A clinical study of pediatric patients with severe scorpion envenomation, comparing those that did and did not receive a corticosteroid together with antivenom, showed that there were no differences between the groups in terms of mortality or length of stay in the intensive care unit [34]. However, the corticosteroid group patients presented systemic manifestations (indicative of more severe envenomation) at admission, which calls into question the conclusion drawn by the authors-that corticosteroid administration does not improve the evolution of cases of severe scorpion envenomation [34]. Therefore, we tested whether dexamethasone has any regulatory effect on the expression of proteins in experimental envenomation. It has been demonstrated that, in alveolar cells, there is an increase of the $\alpha-, \beta-$, and $\gamma-\mathrm{ENaC}$, as well as $\mathrm{Na}, \mathrm{K}-\mathrm{ATPase}$, after exposure to dexamethasone [35-38]. In the present study, dexamethasone administration prevented a venom-induced decrease in $\alpha-\mathrm{ENaC}$ and a venominduced increase NKCC1 expression. However, we observed no difference between the venom group and the dexamethasone + venom group in terms of $\alpha_{1}-\mathrm{Na}, \mathrm{K}$-ATPase expression.

Various studies have shown that, in human and experimental scorpion envenomation, there is inflammatory activation [17-20,39]. Some authors suggest that, in the presence of systemic inflammation, cytokines mediate sodium transporter expression [40]. We investigated the effects of T. serrulatus venom on macrophage infiltration, TLR4 expression in the lung, and serum cytokines. TLRs are expressed in immune cells, such as polymorphonuclear granulocytes, macrophages, dendritic cells, and certain epithelial cells. Engagement of TLR4 initiates signaling through intracellular pathways that lead to activation of transcription factors, including nuclear factor $\mathrm{k}-\mathrm{B}$ and interferon regulatory factor 3 , that transcribe genes such as pro-inflammatory cytokines and other immunoregulatory molecules [25]. T. serrulatus venom induces production of inflammatory mediators in peritoneal macrophages by interacting with TLR2 and TLR4 [41]. Mice inoculated with T. serrulatus venom show increased perivascular infiltration of mononuclear cells in lung tissue as soon as 15 min after injection [42]. In the present study, the number of CD68-positive cells in the lung increased by $60 \mathrm{~min}$ after venom injection, and dexamethasone had no effect on cell infiltration. However, dexamethasone prevented the venom-induced increase in TLR4 expression. In addition, rats inoculated with T. serrulatus venom showed elevated serum levels of IL- 6 , TNF- $\alpha$, and IL-10 by 60 min after envenomation, and dexamethasone did not reduce cytokine concentrations to control group levels.

In our model, animals developed early hypotension, metabolic acidosis, and worsening of the $\mathrm{PaO}_{2} / \mathrm{FIO}_{2}$ ratio. Although we observed a decrease in blood pressure, there 
was no accompanying increase in heart rate, as would be expected. Other authors found that heart rates decreased or not changed significantly after the administration of scorpion venom $[43,44]$.

\title{
Conclusions
}

We have demonstrated that $T$. serrulatus venom impairs the pulmonary expression of sodium and water transporters, as well as increase in inflammatory infiltration and cytokine levels. Together with cardiovascular dysfunction, these initial events might be responsible for the lung injury seen in scorpion envenomation. Our results suggest that T. serrulatus venom and dexamethasone both regulate sodium transport and that TLR4 is one of the pathways by which T. serrulatus venom regulates sodium transport. Further preclinical and clinical studies are warranted in order to elucidate these mechanisms.

\begin{abstract}
Abbreviations
AQP5: aquaporin 5; HR: heart rate; IL: interleukin; MAP: mean arterial pressure; NKCC1: Na-K-2Cl cotransporter; $\mathrm{PaO}_{2} /$ $\mathrm{FIO}_{2}$ : arterial oxygen tension/fraction of inspired oxygen ratio; PEEP: positive end-expiratory pressure; TLR: toll-like

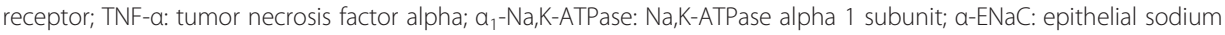
channel alpha subunit.
\end{abstract}

\section{Competing interests}

The authors declare that they have no competing interests.

\section{Authors' contributions}

CMSM conceptualized and designed the paper, acquired the data, analyzed and interpreted the data, drafted and revised the manuscript, and gave final approval for the version to be published. ACB, TRS, RAV, MHS, MIH, and NOSC acquired the data. ACS analyzed and interpreted the data. LA conceptualized and designed the paper, analyzed and interpreted the data, revised the manuscript, and gave final approval for the version to be published. All authors read and approved the final manuscript.

\section{Acknowledgements}

We are grateful to Dr. R. James Turner of the National Institute of Dental and Craniofacial Research (Bethesda, MD) for providing the NKCC1 antibodies and to the Butantan Institute for providing the T. serrulatus venom.

\section{Author details}

${ }^{1}$ Nephrology Department, University of São Paulo School of Medicine, São Paulo, Brazil. ${ }^{2}$ Vital Brazil Hospital, Butantan Institute, São Paulo, Brazil. ${ }^{3}$ Immunology Department, Biomedical Sciences Institute IV, University of São Paulo, São Paulo, Brazil.

Received: 11 March 2015 Accepted: 10 September 2015

Published online: 21 September 2015

\section{References}

1. Chippaux JP, Goyffon M (2008) Epidemiology of scorpionism: a global appraisal. Acta Trop 107:71-79

2. Freire-Maia L, Campos JA, Amaral CF (1994) Approaches to the treatment of scorpion envenoming. Toxicon 32:1009-1014

3. Sistema de Informação de Agravos de Notificação (SINAN, [Brazilian] Case Registry Database) Available at: http://dtr2004.saude.gov.br/sinanweb/novo/ (Accessed February 27 2015).

4. Brasil. Manual de diagnóstico e tratamento de acidentes por animais peçonhentos. Brasília: Fundação Nacional de Saúde, 2001:120 p.

5. Bosnak M, Ece A, Yolbas I, Bosnak V, Kaplan M, Gurkan F (2009) Scorpion sting envenomation in children in southeast Turkey. Wilderness Environ Med 20:118-124

6. Cupo P, Jurca M, Azevedo-Marques MM, Oliveira JS, Hering SE (1994) Severe scorpion envenomation in Brazil. Clinical, laboratory and anatomopathological aspects. Rev Inst Med Trop Sao Paulo 36:67-76

7. Dehesa-Davila M (1989) Epidemiological characteristics of scorpion sting in Leon, Guanajuato, Mexico. Toxicon 27:281-286

8. Sofer S, Gueron M (1988) Respiratory failure in children following envenomation by the scorpion Leiurus quinquestriatus: hemodynamic and neurological aspects. Toxicon 26:931-939

9. Becerril B, Marangoni S, Possani LD (1997) Toxins and genes isolated from scorpions of the genus Tityus. Toxicon 35:821-835

10. Ismail M (1995) The scorpion envenoming syndrome. Toxicon 33:825-858

11. Amaral CF, de Rezende NA, Freire-Maia L (1993) Acute pulmonary edema after Tityus serrulatus scorpion sting in children. Am J Cardiol 71:242-245

12. Benvenuti LA, Douetts KV, Cardoso JL (2002) Myocardial necrosis after envenomation by the scorpion Tityus serrulatus. Trans R Soc Trop Med Hyg 96:275-276

13. Freire-Maia L, Almeida HO, Cunha-Melo JR, Azevedo AD, Barroso J (1978) Mechanism of the pulmonary edema induced by intravenous injection of scorpion toxin in the rat. Agents Actions 8:113-118 
14. Coelho FM, Pessini AC, Coelho AM, Pinho VS, Souza DG, Arantes EC, Teixeira MM, Teixeira AL (2007) Platelet activating factor receptors drive CXC chemokine production, neutrophil influx and edema formation in the lungs of mice injected with Tityus serrulatus venom. Toxicon 50:420-427

15. De Matos IM, Rocha OA, Leite R, Freire-Maia L (1997) Lung oedema induced by Tityus serrulatus scorpion venom in the rat. Comp Biochem Physiol C Pharmacol Toxicol Endocrinol 118:143-148

16. Freire-Maia L, de Matos IM (1993) Heparin or a PAF antagonist (BN-52021) prevents the acute pulmonary edema induced by Tityus serrulatus scorpion venom in the rat. Toxicon 31:1207-1210

17. Fukuhara YD, Reis ML, Dellalibera-Joviliano R, Cunha FQ, Donadi EA (2003) Increased plasma levels of IL-1beta, IL-6, IL-8, IL-10 and TNF-alpha in patients moderately or severely envenomed by Tityus serrulatus scorpion sting. Toxicon 41:49-55

18. Magalhaes MM, Pereira ME, Amaral CF, Rezende NA, Campolina D, Bucaretchi F, Gazzinelli RT, Cunha-Melo JR (1999) Serum levels of cytokines in patients envenomed by Tityus serrulatus scorpion sting. Toxicon 37:1155-1164

19. Pessini AC, de Souza AM, Faccioli LH, Gregorio ZM, Arantes EC (2003) Time course of acute-phase response induced by Tityus serrulatus venom and TSTX-I in mice. Int Immunopharmacol 3:765-774

20. Petricevich VL (2010) Scorpion venom and the inflammatory response. Mediators Inflamm 2010:1-16

21. Matthay MA, Folkesson HG, Clerici C (2002) Lung epithelial fluid transport and the resolution of pulmonary edema. Physiol Rev 82:569-600

22. Sartori C, Matthay MA (2002) Alveolar epithelial fluid transport in acute lung injury: new insights. Eur Respir J 20:1299-1313

23. Matthay MA (2002) Alveolar fluid clearance in patients with ARDS: does it make a difference? Chest 122:340S-343S

24. Comellas AP, Pesce LM, Azzam Z, Saldias FJ, Sznajder Jl (2003) Scorpion venom decreases lung liquid clearance in rats. Am J Respir Crit Care Med 167:1064-1067

25. Lorne E, Dupont H, Abraham E (2010) Toll-like receptors 2 and 4: initiators of non-septic inflammation in critical care medicine? Intensive Care Med 36:1826-1835

26. Cavriani G, Oliveira-Filho RM, Trezena AG, da Silva ZL, Domingos HV, de Arruda MJ, Jancar S, Tavares de Lima W (2004) Lung microvascular permeability and neutrophil recruitment are differently regulated by nitric oxide in a rat model of intestinal ischemia-reperfusion. Eur J Pharmacol 494:241-249

27. Bucaretchi F, Fernandes LC, Fernandes CB, Branco MM, Prado CC, Vieira RJ, De Capitani EM, Hyslop S (2014) Clinical consequences of Tityus bahiensis and Tityus serrulatus scorpion stings in the region of Campinas, southeastern Brazil. Toxicon 89:17-25

28. De Rezende NA, Dias MB, Campolina D, Chavez-Olortegui C, Diniz CR, Amaral CF (1995) Efficacy of antivenom therapy for neutralizing circulating venom antigens in patients stung by Tityus serrulatus scorpions. Am J Trop Med Hyg 52:277-280

29. Berthiaume $Y$, Folkesson HG, Matthay MA (2002) Lung edema clearance: 20 years of progress: invited review: alveolar edema fluid clearance in the injured lung. J Appl Physiol 93:2207-2213

30. O'Neill WC (1999) Physiological significance of volume-regulatory transporters. Am J Physiol 276:C995-C1011

31. Song Y, Yang B, Matthay MA, Ma T, Verkman AS (2000) Role of aquaporin water channels in pleural fluid dynamics. Am J Physiol Cell Physiol 279:C1744-C1750

32. Umenishi F, Carter EP, Yang B, Oliver B, Matthay MA, Verkman AS (1996) Sharp increase in rat lung water channel expression in the perinatal period. Am J Respir Cell Mol Biol 15:673-679

33. Yasui M, Serlachius E, Lofgren M, Belusa R, Nielsen S, Aperia A (1997) Perinatal changes in expression of aquaporin-4 and other water and ion transporters in rat lung. J Physiol 505:3-11

34. Bahloul M, Chaari A, Ammar R, Allala R, Dammak H, Turki O, Chelly H, Ben Hamida C, Bouaziz M (2013) Severe scorpion envenomation among children: does hydrocortisone improve outcome? A case-control study. Trans $R$ Soc Trop Med Hyg 107:349-355

35. Barquin N, Ciccolella DE, Ridge KM, Sznajder JI (1997) Dexamethasone upregulates the Na-K-ATPase in rat alveolar epithelial cells. Am J Physiol 273:L825-L830

36. Dagenais A, Denis C, Vives MF, Girouard S, Masse C, Nguyen T, Yamagata T, Grygorczyk C, Kothary R, Berthiaume Y (2001) Modulation of alpha-ENaC and alpha1-Na +-K+-ATPase by CAMP and dexamethasone in alveolar epithelial cells. Am J Physiol Lung Cell Mol Physiol 281:L217-L230

37. Guney S, Schuler A, Ott A, Hoschele S, Zugel S, Baloglu E, Bartsch P, Mairbaurl H (2007) Dexamethasone prevents transport inhibition by hypoxia in rat lung and alveolar epithelial cells by stimulating activity and expression of $\mathrm{Na}+-\mathrm{K}+-$ ATPase and epithelial Na + channels. Am J Physiol Lung Cell Mol Physiol 293:L1332-L1338

38. Itani OA, Auerbach SD, Husted RF, Volk KA, Ageloff S, Knepper MA, Stokes JB, Thomas CP (2002) Glucocorticoidstimulated lung epithelial $\mathrm{Na}(+)$ transport is associated with regulated $\mathrm{ENaC}$ and sgk1 expression. Am J Physiol Lung Cell Mol Physiol 282:L631-L641

39. Fialho EM, Maciel MC, Silva AC, Reis AS, Assuncao AK, Fortes TS, Silva LA, Guerra RN, Kwasniewski FH, Nascimento FR (2011) Immune cells recruitment and activation by Tityus serrulatus scorpion venom. Toxicon 58:480-485

40. Schmidt C, Hocherl K, Schweda F, Kurtz A, Bucher M (2007) Regulation of renal sodium transporters during severe inflammation. J Am Soc Nephrol 18:1072-1083

41. Zoccal KF, Bitencourt Cda S, Paula-Silva FW, Sorgi CA, de Castro Figueiredo Bordon K, Arantes EC, Faccioli LH (2014) TLR2, TLR4 and CD14 recognize venom-associated molecular patterns from Tityus serrulatus to induce macrophage-derived inflammatory mediators. PLoS One 9:2-12

42. Paneque Peres AC, Nonaka PN, de Carvalho PT, Toyama MH, Silva CA, Vieira RP, Dolhnikoff M, Zamuner SR, de Oliveira LV (2009) Effects of Tityus serrulatus scorpion venom on lung mechanics and inflammation in mice. Toxicon 53:779-785

43. Andrade MV, Caramez MP, Abreu EM, Dolnikoff M, Omar ED, Velasco IT, Cunha-Melo JR (2004) Lung compliance, plasma electrolyte levels and acid-base balance are affected by scorpion envenomation in anesthetized rats under mechanical ventilation. Comp Biochem Physiol C Toxicol Pharmacol 138:97-104

44. Azevedo AD, Silva AB, Cunha-Melo JR, Freire-Maia L (1983) Cardiovascular and respiratory effects induced by a purified scorpion toxin (tityustoxin) in unanesthetized rats. Toxicon 21:753-759 